\title{
Pre-lithiated Mesocarbon Microbeads Anode and Bifunctional Cathode for High Performance Hybrid Lithium-Ion Capacitors
}

\author{
Jing Li ${ }^{*}$, Jianqiang Guo ${ }^{*}$, Pengyu Li, Lige Wang, Yeju Huang \\ School of Materials Science and Engineering, Southwest University of Science and Technology, \\ Mianyang, Sichuan 621010, China \\ *E-mail: 2775262938@qq.com
}

doi: $10.20964 / 2017.04 .59$

Received: 30 December 2016 / Accepted: 21 February 2017 / Published: 12 March 2017

Lithium-ion capacitor (LIC) is a hybridization of two types of electrochemical energy storage system, rechargeable battery and electrochemical double layer capacitor. Scientific researchers have made broad research on the LIC in the past decades. In this paper, we used pre-lithiated mesocarbon microbeads anode and bifunctional cathode including $75 \mathrm{wt} \%$ capacitor material (activated carbon (AC)) and $25 \mathrm{wt} \%$ battery material (lithium iron phosphate (LFP)) to prepare hybrid lithium-ion capacitors (LIC (AC+LFP)). The results show that the as-prepared LIC (AC+LFP) hybrid lithium-ion capacitors exhibit better cycle stability and higher rate performance, compared with the LIC (AC) hybrid lithium-ion capacitors, which only employs AC as cathode matertials. This improved performance is mainly due to the addition of LFP in the cathode electrode.

Keywords: Hybrid lithium-ion capacitor; Pre-lithiated; AC; MCMB ; LFP

\section{$\underline{\text { FULL TEXT }}$}

(C) 2017 The Authors. Published by ESG (www.electrochemsci.org). This article is an open access article distributed under the terms and conditions of the Creative Commons Attribution license (http://creativecommons.org/licenses/by/4.0/). 